\section{The Animal Pigment Bilirubin Identified in Strelitzia reginae, the Bird of Paradise Flower}

\author{
Cary Pirone ${ }^{1}$ \\ Department of Biological Sciences, Florida International University, Miami, \\ FL 33199
}

Jodie V. Johnson

Department of Chemistry, University of Florida, Gainesville, FL 32611

J. Martin E. Quirke

Department of Chemistry and Biochemistry, Florida International

University, Miami, FL 33199

\section{Horacio A. Priestap and David Lee}

Department of Biological Sciences, Florida International University, Miami, FL 33199

\section{Additional index words. tetrapyrrole, pigment, color, MS/MS, HPLC/UV}

\begin{abstract}
Strelitzia reginae Aiton is an iconic plant known for its vibrant orange and blue inflorescences. Floral pigments include carotenoids and the anthocyanin delphinidin-3-rutinoside. S. reginae has black seeds with vivid orange arils, yet the basis for the orange color is unknown. We recently discovered bilirubin in the arils of $S$. nicolai. Previously, this pigment was known only to exist in animals as a breakdown product of heme. Using high-performance liquid chromatography (HPLC) and HPLC/electrospray ionization-tandem mass spectrometry, we now show that bilirubin is the primary aril pigment of $S$. reginae and is also present in low concentrations in its sepals (less than $\left.44.0 \mathrm{ng} \cdot \mathrm{g}^{-1}\right)$.
\end{abstract}

Strelitzia reginae (family Strelitziaceae, order: Zingiberales), the Bird of Paradise plant, is an herbaceous monocot native to South Africa but widely cultivated in warm temperate and tropical regions. Aside from the shape of its inflorescence, which resembles the head of a bird, $S$. reginae is also admired for its brilliant floral coloration. Each flower is composed of three vibrant orange sepals and three blue petals (Fig. 1A). At least 19 carotenoids are present in the sepals (Simpson et al., 1975; Tappi and Menziani, 1955), and the anthocyanin delphinidin- 3-rutinoside is found in the petals (Harbourne, 1967). Anthocyanins are stored in the vacuole of petal cells (Kronsteadt and Walles, 1986), whereas carotenoids in

Received for publication 12 Apr. 2010. Accepted for publication 13 July 2010 .

This research was funded by the U.S. Environmental Protection Agency (EPA) under the Greater Research Opportunities (GRO) Graduate Program and the Office of Research (OSRA) at FIU. Funding for the Finnigan MAT LCQ Classic was provided by NSF CHE 9613678 .

We thank the Center for Ethnobiology and Natural Products (CeNAP) at FIU for laboratory facilities, K.G. Furton for his generous support of H.A. Priestap, T. DeFanti for his images, and C. Husby and D. Ellison for aril material. We thank Waters Corporation for the donation of the C8 high-performance liquid chromatography column.

${ }^{1}$ To whom reprint requests should be addressed; e-mail cpiro001@fiu.edu. mature sepal tissue are stored in spindleshaped chromoplasts (Simpson et al., 1975). Petal color is enhanced by papillar processes in the epidermis, which refract light (Kronsteadt and Walles, 1986).

In contrast to the conspicuous flowers, the capsular fruit of $S$. reginae is pale and partially obscured by the bract during development. However, at maturity, the capsule breaks open to reveal intensely colored orange arillate seeds (Fig. 1B-C). Remarkably, aril color remains unchanged years after cell death, a quality that likely contributes to the continued attraction of avian frugivores (Frost, 1980). We recently found the orange tetrapyrrole bilirubin to be the primary pigment in the arils of Strelitzia nicolai, a close relative of $S$. reginae (Pirone et al., 2009). Bilirubin was previously known in the animal kingdom where it is produced as a breakdown product of heme. Preliminary high-performance liquid chromatography (HPLC) and ultraviolet-visible (ultraviolet) spectrometry analyses suggested that bilirubin is also present in the arils of $S$. reginae. We were therefore interested in whether this unusual pigment is indeed present in those arils and whether it is also present in the flowers. We used HPLC/ultraviolet and HPLC/ultraviolet/electrospray ionization-tandem mass spectrometry (HPLC/ ultraviolet/ESI-MS/MS) to investigate these questions. We also observed the aril cells using light microscopy to determine the location of pigment within the aril and sepal cells.
Sepal tissue was collected from a single clonal plant at Fairchild Tropical Botanic Gardens in Miami, FL. Aril tissue was obtained from two plants at Ellison Horticulture Pty Ltd. in Allston, Australia. It was not possible to analyze aril and sepal tissue from the same individuals. S. reginae flowers in Miami but does not set fruit. Bilirubin is known to decompose in heat, light, and oxygen. Preliminary analyses did not indicate that bilirubin is stable in sepal tissue, but they did suggest that bilirubin is stable in aril tissue for at least several months, likely as a result of the high lipid content of the tissue. Therefore, it was necessary to analyze fresh sepal tissue from local plants, but it was possible to analyze imported aril tissue.

For each sepal sample, $20.0 \mathrm{~g}$ of fresh tissue was ground in a blender with $100 \mathrm{~mL}$ methanol for 2 min and was then filtered through a Buchner funnel. The residue was re-extracted with $50 \mathrm{~mL}$ of chloroform in a mortar and pestle, and this procedure was repeated until sepals were colorless. Methanol and chloroform extracts were pooled, and $100 \mathrm{~mL}$ of water was added. The mixture was left in a separatory funnel for $5 \mathrm{~min}$ and then the (lower) chloroform layer was collected, filtered with a polytetrafluoroethylene $0.2-\mu \mathrm{m}$ filter, and divided into two equal aliquots. Each aliquot was dried to completion in a rotovap at $30{ }^{\circ} \mathrm{C}$. For each aril sample, $0.05 \mathrm{~g}$ tissue from a single aril was ground by a mortar and pestle and extracted with chloroform repeatedly until the chloroform extracts were colorless. As described previously, the chloroform extract was filtered, divided into two equal aliquots, and dried on a rotovap. Sepal and aril tissue were sampled in duplicate. To determine the presence of bilirubin, one aliquot from each sample was analyzed by HPLC and the second aliquot was analyzed by HPLC/ESI-MS/MS.

High-performance liquid chromatography/ultraviolet. HPLC/ultraviolet analyses were performed on a Thermo-Finnigan SpectraSystem HPLC apparatus with a variable wavelength PDA detector (SMC1000, P4000, AS3000, UV6000LP; Thermo Electro Corporation, San Jose, CA). Extract was redissolved in dimethylsulfoxide (DMSO), partitioned with hexane to remove lipids, and chromatographed on a reverse-phase ODS-A column ( $5 \mu \mathrm{m}, 150$ $\mathrm{mm} \times 4.3 \mathrm{~mm}$ i.d.; Waters Corporation, Milford, MA). Mobile phase A was $0.1 \%$ formic acid in methanol, and mobile phase B was $0.1 \%$ formic acid in water. The HPLC gradient (at 1.0 $\mathrm{mL} \cdot \mathrm{min}^{-1}$ ) was started at $40 \% \mathrm{~A}$ and increased linearly to $95 \%$ A over $40 \mathrm{~min}$, then held constant at $95 \% \mathrm{~A}$ and $5 \% \mathrm{~B}$ for $10 \mathrm{~min}$. Bilirubin was identified by comparing the retention time and ultraviolet-visible spectra of $S$. reginae pigments with bilirubin standard (Sigma-Aldrich, St. Louis, MO), which had a retention time of $42.9 \mathrm{~min}$ and a maximum absorbance at $444 \mathrm{~nm}$ in the HPLC solvent system described previously. Bilirubin concentrations were determined by comparison with a standard curve $\left[\left(R^{2}=0.995\right)\right.$ estimated 

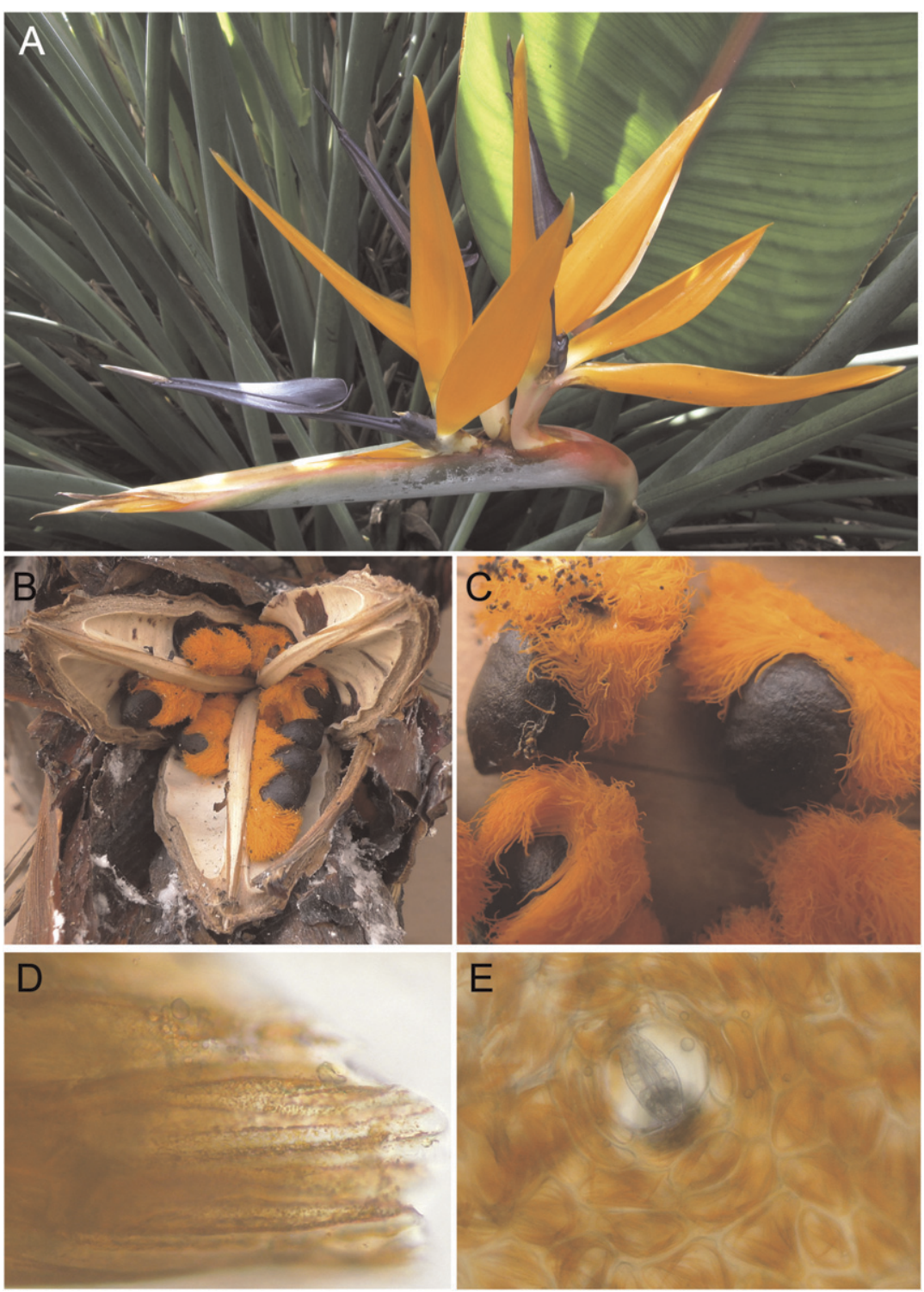

Fig. 1. Strelitzia reginae. (A) Inflorescence of $S$. reginae photographed at Fairchild Tropical Botanic Garden. Inflorescence is $\approx 22 \mathrm{~cm}$ long. (B) Mature and open capsule of $S$. reginae with arillate seeds exposed, capsules $\approx 5.5 \mathrm{~cm}$ across. Photographed in Del Mar, CA, by Tom DeFanti. (C) Arillate seeds of $S$. reginae, seeds $\approx 4 \mathrm{~mm}$ in diameter, photographed by Tom DeFanti. (D) Aril fibers of $S$. reginae, in longitudinal view. Bilirubin is present in the crystalline granules attached to inner cell wall of these dead cells. Length of image $=300 \mu \mathrm{m}$. (E) Paradermal view of epidermal cells of orange sepals of S. reginae. Bilirubin granules are not seen in these cells, the color produced primarily by carotenoids in large chromoplasts. Length of image $=300 \mathrm{~nm}$.

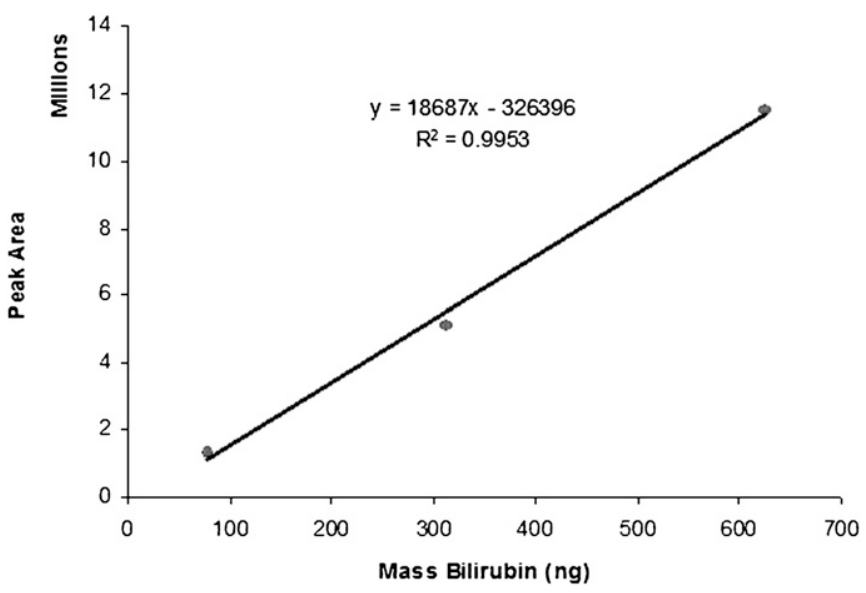

Fig. 2. High-performance liquid chromatography standard curve of bilirubin-IX $\alpha$. detection limit $=20 \mathrm{ng}$ injected on column] (Fig. 2).

Preliminary analysis of sepal tissue showed compounds that eluted at retention times similar to that of bilirubin. The ultraviolet-visible spectra of these compounds were similar to carotenoids. To avoid the possible overlap of the HPLC/ultraviolet spectra of these pigments with that of bilirubin, we treated sepals with diazomethane to convert bilirubin to its dimethyl ester, i.e., both carboxylic acids were converted to methyl esters $\left(\lambda_{\max }=453 \mathrm{~nm}\right.$ in HPLC solvents described previously) (Kuenzle et al., 1973). Diazomethane was prepared from diazald according to the method of Vogel et al. (1989). Chloroform extracts of the sepals were treated with an excess of a solution of diazomethane to form the bilirubin dimethyl ester. The addition of the diazomethane was deemed to be complete when effervescence was no longer observed. The excess diazomethane was destroyed by the addition of a few drops of acetic acid. Although the diazomethane would also methylate any other carboxylic acid impurities in the extract, such ester byproducts did not interfere in any way with the observance of the bilirubin dimethyl ester peak in the HPLC analyses. Thus, it was unnecessary to carry out additional purification of the of the sepal extracts. The retention time of bilirubin dimethyl ester was $31.7 \mathrm{~min}$, thus enabling us to observe it without the interference of the other pigments. A standard curve for bilirubin dimethyl ester $\left[\left(R^{2}=1\right)\right.$, estimated detection limit $=35.0 \mathrm{ng}$ injected on column] was constructed by treating bilirubin standard with diazomethane. Identification of the peak at $31.7 \mathrm{~min}$ as bilirubin dimethyl ester was verified by comparison with bilirubin dimethyl ester standard (Frontier Scientific, Logan, UT), which also eluted at $31.7 \mathrm{~min}$. For samples in which bilirubin was detected by HPLC/ESI-MS/MS but not HPLC/ultraviolet, we assumed the mass of bilirubin to be less than the estimated detection limit of bilirubin or bilirubin treated with diazomethane. SD values were not calculated as a result of the low sample size of two. Instead, concentration values for both samples of aril and sepal tissue are presented in Table 1 .

High-performance liquid chromatography/ ultraviolet/electrosprayionization-tandem mass spectrometry. The plant extract was redissolved in DMSO (Certified ACS; Fisher Scientific, Pittsburgh, PA) and analyzed by reverse-phase C8 HPLC/ultraviolet/ESI-MS/ MS using both positive and negative ESI and a number of different MS scans. HPLC/ ultraviolet was performed with an Agilent Technologies HPLC with binary pumps (1100 series; Santa Clara, CA), a Symmetry C8 HPLC column $(5 \mu \mathrm{m}, 2.1 \times 150 \mathrm{~mm}$; Waters Corporation), and an Agilent ultraviolet-visible detector (G1314A). The mobile phase A

Table 1. Concentration of bilirubin in $S$. reginae arils and sepals.

\begin{tabular}{lcc}
\hline Sample & Aril & Sepal \\
\hline 1 & $21.97 \mathrm{mg} / \mathrm{g}$ & $<44 \mathrm{ng} / \mathrm{g}$ \\
2 & $12.82 \mathrm{mg} / \mathrm{g}$ & $<44 \mathrm{ng} / \mathrm{g}$ \\
\hline
\end{tabular}

HortScience Vol. 45(9) September 2010 

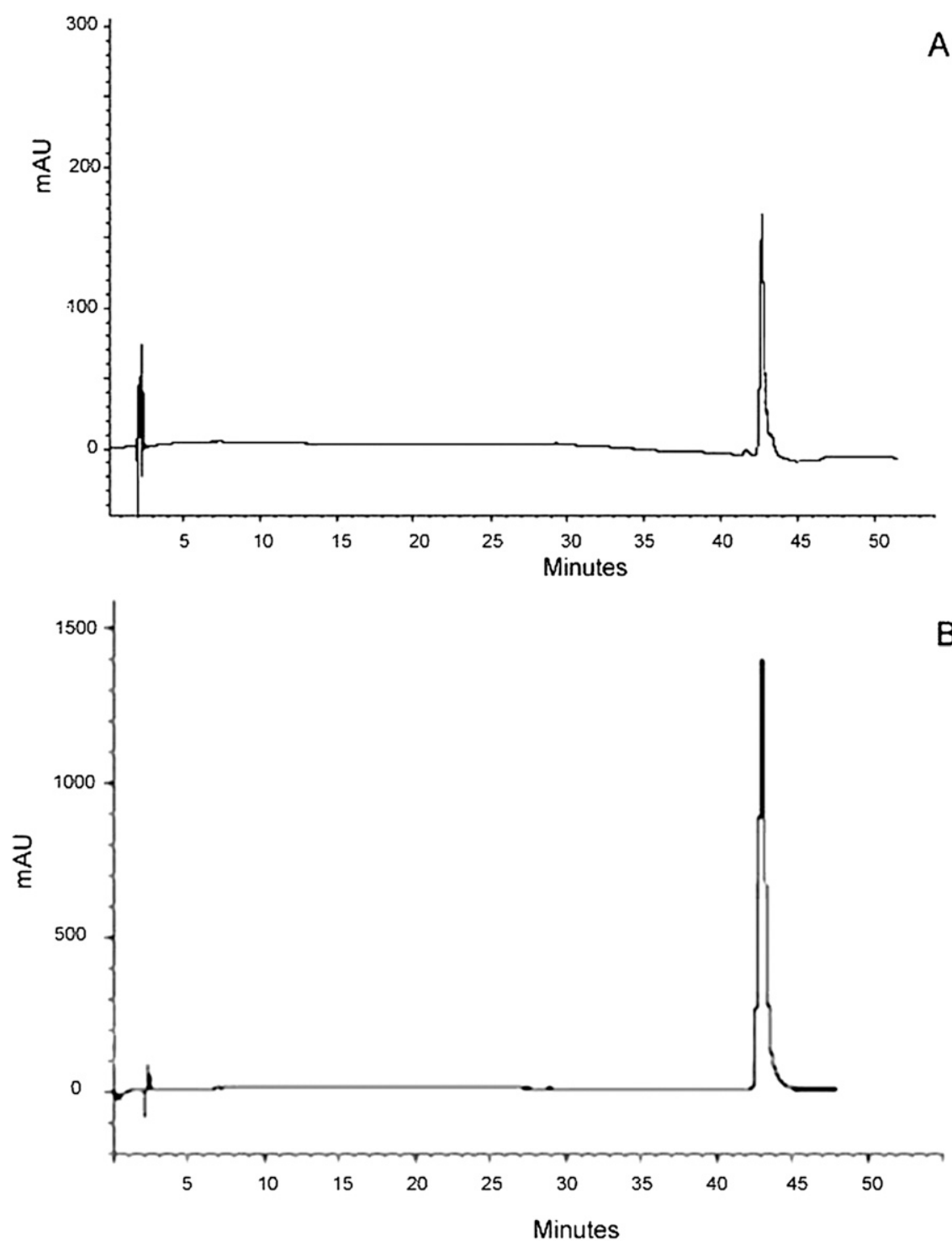

Fig. 3. High-performance liquid chromatography chromatograms of (A) bilirubin standard and (B) aril extract of $S$. reginae. was $0.2 \%$ acetic acid [glacial, biochemical grade $(99.8 \%)$; ACROS Organics, Morris Plains, NJ, USA) in $\mathrm{H}_{2} \mathrm{O}$ (HPLC grade, Honeywell Burdick \& Jackson, Muskegon, $\mathrm{MI}$ ] and mobile phase B was $0.2 \%$ acetic acid in acetonitrile (LC-MS grade; Honeywell Burdick \& Jackson). The HPLC gradient (at $0.2 \mathrm{~mL} \cdot \mathrm{min}^{-1}$ ) was started at $20 \% \mathrm{~B}$ at time 0 and increased linearly to $85 \%$ B over 30 min and then increased linearly to $100 \% \mathrm{~B}$ over $15 \mathrm{~min}$. The column was held at $100 \%$ $\mathrm{B}$ until monitoring of the ultraviolet/MS signal showed no further elution of peaks. For some extracts, this was more than $150 \mathrm{~min}$. The ultraviolet-visible response was monitored at $450 \mathrm{~nm}$ for bilirubin, which eluted at $\approx 39 \mathrm{~min}$.

All mass spectrometry data were obtained with a Finnigan MAT (San Jose, CA) LCQ classic quadrupole ion trap mass spectrometer equipped with an ESI. The ESI was operated with a nitrogen sheath and auxiliary gas flows of 65 and 5, respectively (unitless, software parameter) with a spray voltage of $3.3 \mathrm{kV}$ and a heated capillary temperature of $250{ }^{\circ} \mathrm{C}$. The heated capillary voltage was $+15 \mathrm{~V}$ and $-22 \mathrm{~V}$ for $(+)$ and $(-)$ ESI, respectively, whereas the tube lens was operated at $0 \mathrm{~V}$ for both ESI polarities. Collision-induced dissociation (CID) was conducted with a parent ion isolation of $3 \mathrm{u}$, CID energy of $37.5 \%$, qCID of 0.25 , and CID time of $30 \mathrm{~ms}$.

With $(+)$ ESI, bilirubin produced an $\mathrm{m} / \mathrm{z}$ $585[\mathrm{M}+\mathrm{H}]+$ ion and an $\mathrm{m} / \mathrm{z} 583$ ion as a result of oxidation during ionization. The $\mathrm{m} / \mathrm{z} 585$ and $\mathrm{m} / \mathrm{z} 583$ ions underwent CID-MS/MS to form $\mathrm{m} / \mathrm{z} 299$, and 297 ions, respectively, as major product ions. With (-) ESI-MS, bilirubin produced $\mathrm{m} / \mathrm{z} 583[\mathrm{M}-\mathrm{H}]-$ and $\mathrm{m} / \mathrm{z} 581$ ions, which were dissociated to form $\mathrm{m} / \mathrm{z} 285$ and 537 major product ions, respectively. Bilirubin was identified in the plant extracts by matching of retention time and $(+)$ and $(-)$ ESI-MS and-MS/MS spectra with those of an authentic bilirubin standard.
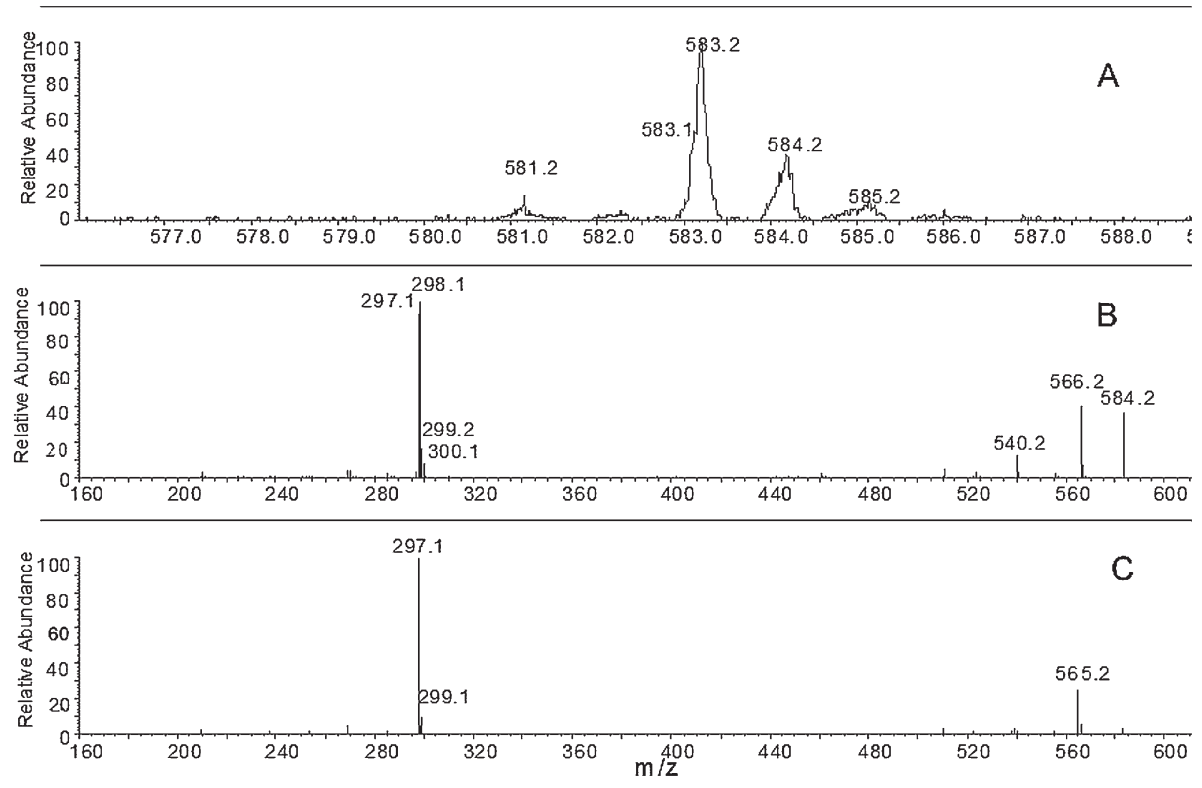

Fig. 4. Bilirubin standard by (+) ESI-zoom-MS and MS/MS: (A) zoom-MS of molecular ion region; (B) product spectrum of $\mathrm{m} / \mathrm{z} 585 ;(\mathbf{C})$ product spectrum of m/z 583. ESI-MS = electrospray ionization-mass spectrometry. 
DMSO solvent blanks were analyzed before and after analyses of each extract and after analyses of bilirubin standards to control for carryover of bilirubin. These DMSO blanks were repeated if significant levels of bilirubin were carried over.

Microscopy. Sepal and aril tissues were observed in a Leica Model DME brightfield compound microscope with a $40 \times$ objective and photographed using a Nikon CoolPix 4500 camera $(2272 \times 1704$ pixels $)$. Tissues were sectioned by hand and mounted in water.

\section{Results and Discussion}

Bilirubin was present in both the aril and sepal extracts of $S$. reginae. Each HPLC/ ultraviolet analysis of the aril extracts showed a single peak with retention time and ultraviolet-visible spectrum that matched those of the bilirubin standard (Fig. 3). Bilirubin identification was confirmed by HPLC/ESI-MS/MS (Figs. 4 and 5). Bilirubin was also identified in sepal samples by HPLC/ESI-MS/MS (Fig. 6) but was not detected by HPLC/ultraviolet, even after treatment with diazomethane. The concentration of bilirubin in the sepals was less than $44.0 \mathrm{ng} \cdot \mathrm{g}^{-1}$ of fresh tissue $(\mathrm{n}=2)$, whereas the average concentration in the aril was $17.4 \mathrm{mg} \cdot \mathrm{g}^{-1}$ fresh tissue $(\mathrm{n}=2)$ (see Table 1 for concentration values of all samples).

The low sample size was adequate for ensuring the detection of bilirubin in $S$. reginae, because false-positives may have occurred through contamination of the sample or the equipment but not by chance alone. Contamination was avoided by the washing of glassware multiple times (soap and water, acetone, chloroform), the use of disposable
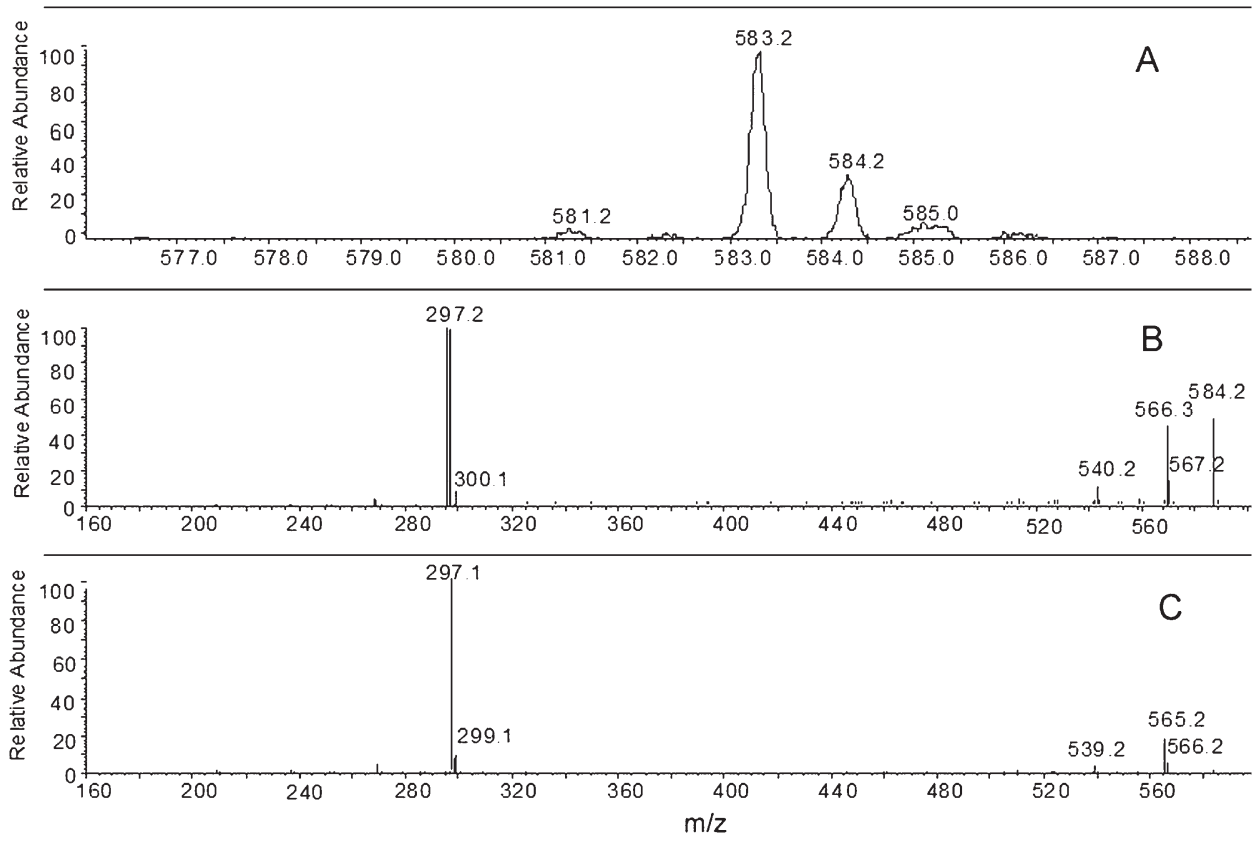

Fig. 5. Bilirubin in S. reginae aril by (+) ESI-MS and MS/MS: (A) zoom-MS of molecular ion region; (B) product spectrum of $\mathrm{m} / \mathrm{z} 585 ;(\mathbf{C})$ product spectrum of $\mathrm{m} / \mathrm{z}$ 583. ESI-MS = electrospray ionization-mass spectrometry.

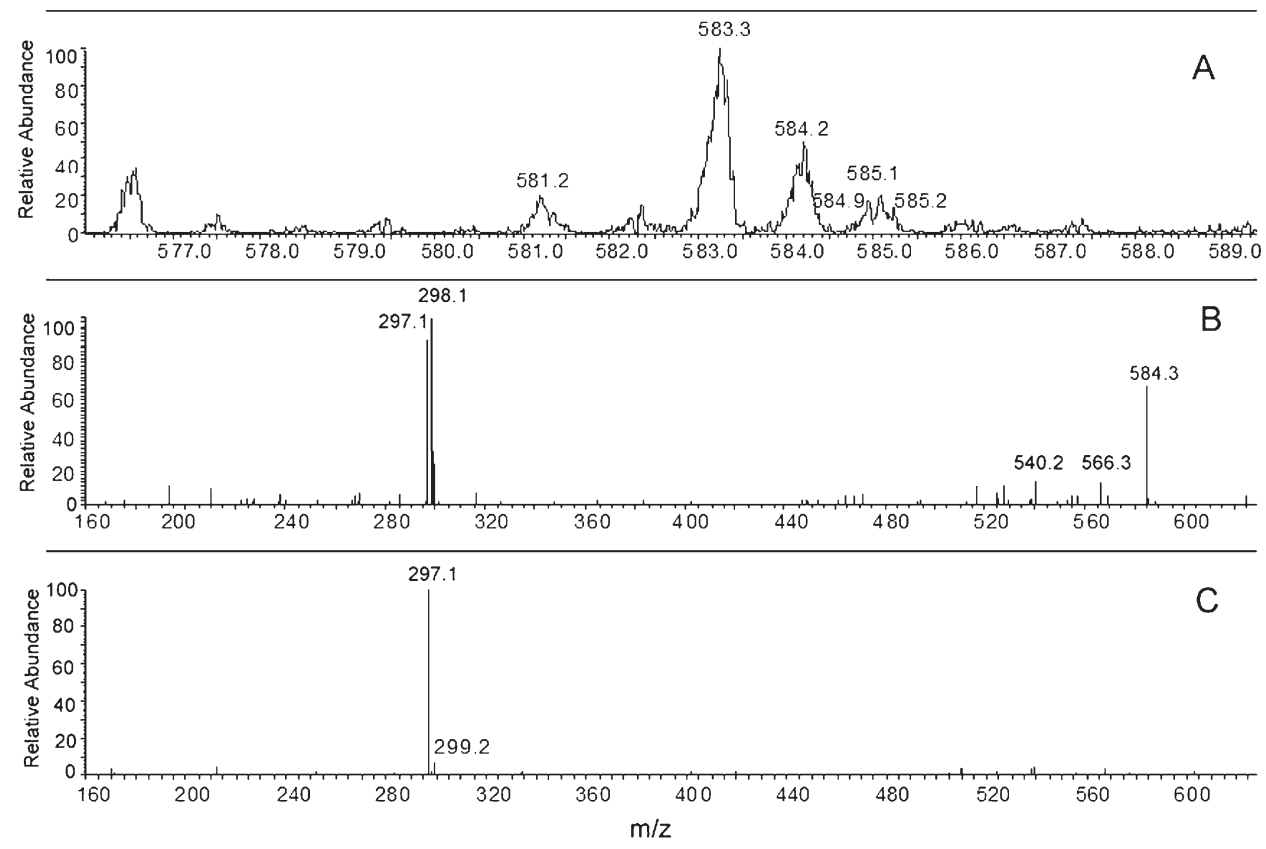

Fig. 6. Bilirubin in S. reginae sepal extract by (+) ESI-Zoom-MS and MS/MS: (A) zoom-MS of molecular ion region; (B) product spectrum of m/z 585; (C) product spectrum of $\mathrm{m} / \mathrm{z} 5$. ESI-MS = electrospray ionization-mass spectrometry. 
vials when possible, and changing gloves after the analysis of each sample. Blank(s) were run between all chromatographic procedures to avoid the carryover of bilirubin between samples and ensure a flat baseline.

In the arils, bilirubin is not only present in high concentration, but it is also the primary pigment and is thus responsible for color production. In contrast, it is likely that the low concentration of bilirubin in the sepals precludes it from contributing significantly to color. Furthermore, high concentrations of sepal carotenoids (Simpson et al., 1975; Tappi and Menziani, 1955) likely mask low levels of bilirubin. Whether bilirubin serves a function other than color production in $S$. reginae remains unclear.

In mature aril tissue, bilirubin was present as granular bodies irregularly distributed throughout the cell (Fig. 1D). In mature sepal tissue, we observed elongate structures (Fig. $1 \mathrm{E})$, which were previously identified as containing carotenoids (Simpson et al., 1975). We saw no evidence of pigment bodies that might contain bilirubin.

This study provides new insight into color production in an iconic tropical plant.

It also demonstrates the first example of bilirubin in a flower and verifies the presence of bilirubin in a plant species other than $S$. nicolai. Coupled with further research on the function, distribution, and synthesis of bilirubin in plants, this information may be of use for practical applications such as the manipulation of color through breeding and genetics.

\section{Literature Cited}

Frost, P.G.H. 1980. Fruit-frugivore interactions in a South African coastal dune forest. Proc. Int. Ornith. Congress. p. 1179-1184.
Harbourne, J.B. 1967. Comparative biochemistry of the flavonoids. Academic Press, New York, NY.

Kronsteadt, E.C. and B. Walles. 1986. Anatomy of the Strelitzia reginae flower (Strelitziaceae). Nord. J. Bot. 6:307-320.

Kuenzle, C.C., M.H. Weibel, and R.R. Pelloni. 1973. The reaction of bilirubin with diazomethane. Biochem. J. 133:357-368.

Pirone, C.L., J.M.E. Quirke, H. Priestap, and D.W. Lee. 2009. Animal pigment bilirubin discovered in plants. J. Amer. Chem. Soc. 131:2830.

Simpson, D.J., M.R. Baqar, and T.H. Lee. 1975. Ultrastructure and carotenoid composition of chromoplasts of the sepals of Strelitzia reginae Aiton during floral development. Ann. Bot. (Lond.) 39:175-183.

Tappi, G. and E. Menziani. 1955. Sui carotenoidi di Strelitzia reginae. Gazz. Chim. Ital. 85:720-724.

Vogel, A.I., B.S. Furnis, A.J. Hannaford, P.W.G Smith, and A.R. Tatchell. 1989. Textbook of practical organic chemistry. Pearson Prentice Hall, Harlow, UK. 